\title{
On the Artistic Beauty of the Product Design
}

\author{
FEI HE \\ ${ }^{1}$ School of Art And Design, Jingdezhen Ceramic Institute,Jiangxi,China \\ ah_fei1225@126.com
}

\begin{abstract}
Keywords: product design;artistic mood;way of thingking
Abstract. This article discusses the issues of the art and innovation of the products from it's artistic form of "artistic mood". It has been showed that "artistic beauty" appears not only in the literature, but in the design of architecture, garden and products, also, the expression of the "artistic mood" plays an important role in the process of product design. Therefore, an outstanding products should be rich with "artistic mood". At the same time, "artistic mood" expressed in the product should be a reproduction of designers' thinking and feelings, but it's not simply a reproduction of the designer's own feeling and thinking, consumers' emotional factors should be taken into account as well. Then, article analyzes the "artistic mood", thinking process of the products, and the essence of it is to closely relate factors of "man - machine - environment". Thus, to recognize that products design should be a bridge between technology and human culture. The pursuit of product design should be viable and humane, and there should be beauty, lease of life and warmth in it.
\end{abstract}

\section{Introduction}

An important principle of industrial design is "people-oriented", a study of the harmonious relationship between man and nature. Besides, to have a more rational combination of function, structure, shape, color and other elements of the products through designing the products, and meeting the both material and spiritual needs of the majorities. "Artistic mood", as a distinct category of Chinese classical aesthetics, is an integral part in the designing process. It is a reproduction of designer's thinking, feeling and intention, and of human's material life. The ultimate goal of "artistic mood" is to achieve the scenes and artistic truthfulness.

\section{"Artistic mood" is the the Ultimate Goal of Art}

The explanation of "“artistic mood" in the Modern Chinese Dictionary is that "artistic mood and state is shaped through the image description of a literary and artistic work". For example, when we read the renowned verses like "Amid the falling blooms alone stand I, in the fine rain a pair of swallows fly", and "A little boat, a bamboo cloak, an old man fishing in the cold river-snow", we will inevitably praise that these verses truly have some excellent artistic moods. In addition, Zhang Can, the great painter in Tang Dynasty, also stated during creating process that "nature outside, in the heart of the source." This is considered as the overview of the artistic mood. Zhang Can thought that artistic mood is a crystalline form of life which is deriving from the combination of "fate" (nature creator, or natural) and "the source of heart" (the feelings). For instance, the verse like "orioles flying and fish diving, dainty and exquisite" express the means of artistic mood. Artistic mood not only expressed in the poem and painting, in fact, it is stressed in many graphics, advertising, architecture and landscape art in every life. The so-called "predecessors wrote the lyrics, the latter described the scene" is the meaning of it. In the meanwhile, artistic mood deliver the means of national characteristics in the category of Chinese classical aesthetics and artistic theory, and play the core role and contribute the most in the long history of Chinese culture. In China, the appearance of artistic mood can be traced back to Zhuangzi's thought of "co-exist with Heaven and Earth, and united with everything." It acts as the aesthetic theory foundation for the "artistic concept", such as "united with everything", "subject and object is one" and "Blending emotion with scenery". 
Liu Yuxi from the Tang Dynasty, his "artistic conception resulting from image" (Story of Dong's Wuling)can be deemed as the most concise and the most accurate summary of the aesthetic essence of artistic mood. The so-called "artistic conception resulting from image" is that "artistic conception" is regarded as the breakthrough and transcend of "image" which is limited by time and space. "artistic conception" is "image" as well, but the former one tends to be infinitely close to the nothingness of "artistic conception" in the point of time and space, it can be illustrated that it is an unity of "image" and "the things outside the image". "The things outside the image" is a breakthrough of the finite "image", but not have not completely getting rid of the "image". What Tang Dynasty's esthetician stated about "artistic mood" or "image" is that it is not some kind of finite "image", but the infinite "image" that has broken it's limited image. It is the "image" that binds the actual and the visual conditions.In short, "artistic mood" is presented in the "image" and transcends it. It does not only obtain the depth of the "image", but the profundity of it. In other words, "image" is concrete, and it presents the world limitly, "artistic mood", however, is abstract, and it presents a whole picture of life.

From the above, we can draw the conclusion that "artistic mood" mainly refers to the use of artistic images on the basis of the blending of the subject and object, and forgetting myself and anything else. It leads it's believers to the realm that has transcend the time and space, and that contains all means of metaphysical noumenon. Artistic mood is the ultimate objective of all the arts, and an indispensable factor in art aesthetics. In comparison with the western arts, artistic mood can rather highlight the national characteristics of pursuit of "artistic mood" of Chinese arts. Western artists in ancient time are committed to reproduce a specific images, their focus are on a specific and limited object. Chinese artists, however, tend to not to simply present an individual or an object, but to portray a finite object in a very authentic and perfect way. Their intention is to breakthrough an finite object, and pursue a mood of "an image outside an image", and "view beyond view", from which they express their thoughts about lives.

"Artistic mood" can be reckoned as "artistic conception". "artistic conception" means that the activity of thinking before painting and creative activities as such. However, "artistic mood" normally not only refers to an artist or designer thinking activities prior to the establishment of the works, but to an artistic realm demonstrated after its establishment of works.

For instance, Japan, a nation deeply influenced by Chinese traditional culture, has artists who think that "artistic mood" is an indispensable part of the work of life as well. Therefore, you will have a sense of snowflakes falling quietly from many Japanese graphic design. These works do not deliver a sense of violence delivered from western works, there have no conflict or climax, but more of delicacy and lyrical calm. They depicted a world inseparable of dream and reality with cold strokes and calm. These works are based on the traditional Japanese ethereal nothingness ideology, with a sense of sentiment since ancient times of Japan. Besides, they all pursue the beauty and glamorous feeling from it. On the one hand, these works inherited the aesthetic sense of the Japanese dynasty literature, on the other hand, these works are often depicted with cold strokes. Thus, "artistic mood" exists in all the fine works, and it is the ultimate goal of all artists.

\section{Artistic Function in the Product}

Like literature art, landscape art, and painting, product design have it's own artistic function. When you see a product, whether you like it or not, the shape, color, and decoration can always have an impact on you, regulating the emotion and bringing association. These are the artistic function of a product design, outstanding product design can bring individuals happiness, the love of life, and the pursuit of innovation. Poor works, however, may give rise to depression, sense of disgust and irritability. Product design, due to it's unique expression, stands in the center of produce and all kinds of activities of human society. Product design, as a special artistic function, influences every individual around it all the time, and they are writing the history, technology, desire and hope of human. They are not simply the creator, but the educators as well. 
Form Design. Form design is the major component of product design. Tens of thousands of different product forms have gradually formed their own artistic conception of language, such as product size: large represents noble; Small shows exquisite and precision. The product line represents a solemn, dignity, focus, and discipline. While, curve represents lively, changing, fun and friendly. The compacting feeling in the product gives people the feeling of safe and cleanness, it is the symbol of firm, power and isolation. However, curve shape give people a sense of emptiness, it is the symbol of warm and lively. The extension form of product give people a sense of hope and reflection.

The Use of Color. Our world is colorful. The people of various countries and regions in the long-term work and life created their own distinctive color language. The meaning of it are quite various, and the influence it exerted on people are quite obvious. Throughout history, many poets are adept at using color to create a mood they want to treasure, for example, Bai Juyi's Dreaming of the South "Over the waves the sun glows, redder than fire, and the spring water flows, as blue as sapphire", which shows an excellent combination of color and views. It is not only elegant and catchy, but depicts a beautiful artistic mood, and gives readers a poetic atmosphere. Therefore, when we study the artistic mood inherented in the product design, more attention should be paid to the use of color.

Whether a design work gives a sense of vibrant, stable, and lonely, or warm, and cold are based on the tone color of the work, which includes hue, lightness, purity, size and other factors.

According to the majority's habits in our country, the color often brings a feeling of association to individuals, and the greater the use of the area for each color, the higher the brightness or the greater the purity, the more different it's meaning, feeling and association. The use of gray or medium brightness colors make people feel sense of simplicity from the product. The high purity warm colors coupled with strong brightness contrast gives people a sense of gorgeousness. Large use of cool color in the product gives people a sense of rationality. While using multi-color in the product gives people sense of softness and lovelyness. Using strong contrast hue or bright and high purity hue gives people a sense of markedness, in the meantime, creats a sense of speed.

The use of Decoration. Decoration can help to creat the artistic mood in the product as well, which plays a role of bringing out the theme and emotional sublimation. If properly done, it can always bring out the crucial point, and makes product more poetic, and thought-provoking. In addition, decorations including member processing, selection of materials, facade arrangement and so on can always bring out the artistic mood of the products. For instance, an Arab porcelain plant has launched s set of porcelain tableware series called "Saaristo", Merkel Liewer, the designer of the series, used milky white porcelain body for the porcelain tableware decorated with blue-gray sides. He tries to combine the plump shape of reef, the soft gray of pebble and the feeling of freedom and independence together, and through which to convey a sense of indescribable beauty, and evoking memories of life and experiences at sea of users.

\section{Product and Artistic Mood}

In the History of the Song and Yuan Drama, Wang Guowei once stated that " the best place in Yuan drama is not in its ideological structure, but in his article, the goodness in the article, in short, is that it's full of artistic mood." It can been seen that the "mood" is the center of all the arts center, and play an indispensible role in the works' aesthetics. Hence, a good product design should be full of artistic mood.

"Implication" is another side of "artistic mood", which mainly embodied in language arts--- in literature, he pursue the endless charm, and advocate "the beauty of implication". "Implication" is of crucial in product design. It is said in Yi Zhuan: The Great Appendix that "The Master said: "The written characters are not the full exponent of speech, and speech is not the full expression of ideas; is it impossible then to discover the ideas of the sages?"', which means that though speech can not fully express ideas, the images can, and the difficulties of fully express ideas by speech can be solved through "making images to fully express the ideas". The product are the "image", and the intention, or "speech" of the designer can be demonstrated through his work. Consumers can learn the designers thoughts, 
feelings and pursuits through the product. A bridge has been built among consumers, designers and product through implication, which is a way to present beauty of the work as well.

Mr. Zhu Guangqian once said "implication, which convey infinite meanings, is better than speech, which is finite, therefore, all is understood, and no words are necessary. The reason why literature is attractive is that it include both speech and implication." To put it simply, product and literature are the same, the beauty of the product is not only that the part has been performed, but the larger part that are subtlely expressed. This is the so-called "the beauty of implication" of the product.

Ancient people perhaps can "buy a few acres of land and spring" to pacify their own souls, but today, in this busy and crowded world, people are like pieces of wood floating on the flooded river, and they don't know where they are heading. But what's noble about a man also lays in the unsettling heart that we have in looking for the final home. Many designers also dedicated in expressing the artistic beauty in their work. In the mean time, they wish that the consumer will appreciate their unsaid beauty. Take the recently popularized "sticking lamp" for example, the material of its lamp lid is made of a special thing which allows users to build it into many forms. The base of the lamp is made of the traditional pottery. The designer aims to contrast the modern and ancient beauty to create an unique atmosphere. To German designer Ingo Maurer, he prefers to be called a poet. He wrote poetry with his design language. You can feel the strongly the atmosphere he created by the shattering leaves and the sound of wind and rain in his works. Undoubtedly, different people will have different feelings towards this beauty in different circumstance. But users can obtain more complex and deeper feelings and fun based on these factor and followed the symbolic indications of the poetic language. The works from the Belgium designing company Enthoven Associates also is an embodiment of this view of designing. Their works contains a trace of cleanness. For instance, Bigoma sofa. It's fun, a little exaggerated, but not too much; Another work from the same company is the bright-colored TV stand and book shelf. Both of them overflow with the fast and bright air of life. Observe the works of Enthoven Associates designing company in detail, you might feel like you are inside a small town of Belgium. A sweet and quiet life atmosphere will slowly surround you. All the designers mentioned above injected "life" into the ordinary furniture, which made the environment around it echoed with liveliness. And therefore, it injected the wealthy and relaxed life the color of the culture.

In fact, the foundation of the product design is the "truthfulness" and "sincerity". What the designer truly feels, thinks, and experienced has been injected into the work. It is a process of recreating the meaning of the life from people's material life. Through the designer, the feelings is penetrated from the material into the soul, and becomes the "artistic beauty". This makes the common and ordinary thing becomes unusual with deep meanings, and showed its unobserved beauty, which extends to a artistic level mixed with sentiments and objects.

\section{Conclusion}

The product design reflects people's subjective will, and is based on the objective world and the subjective understanding of the world. It is coordinating the relationship between people and the product. As to create an man-made atmosphere, "Mood" is also a way of thinking for the product design. In addition to the expression of a specific substance features, the most important function of it is to reflect a certain social spirit, the humanistic ideals, to express a certain culture, rather than simply stack its function. Therefore, reflecting Artistic Beauty in the product is a coordination of relations between "man-machine-environment". This satisfy people's yearning and emotional demand for spiritual life in an increasingly materialistic society. It stimulated people's love for beautiful things. This is perhaps the realistic meaning that we explore in discussing "the artistic beauty of product design".

\section{References}

[1] Zihua Qiu: Oriental Arts and Aesthetics,Beijing: Higher Education Press, 2004

[2] Baihua Zong: The Birth of Chinese Artistic Conception, Anhui: Anhui Education Press, 2000 
[3] Haiwen Zhang: Belgian Lifestyle Product Design, 2004, (2) 